\title{
Analysis of Seafloor Sediment Distribution using Multibeam Backscatter Data
}

\author{
Danar G Pratomo ${ }^{1, *}$, Khomsin ${ }^{1}$, Mokhammad $N$ Cahyadi $^{1}$, Kamila Akbar ${ }^{1}$, and Evasari \\ Aprilia $^{1}$
}

${ }^{1}$ Geomatics Engineering Department, Faculty of Civil Engineering, Environment, and GeoEngineering, Institut Teknologi Sepuluh Nopember, Surabaya, Indonesia

\begin{abstract}
Multibeam sonars use an acoustic wave to provide a view of seafloor topography and collect its backscatter. Seafloor backscatter image can be used as a means of quantitative classification of seafloor lithology. This allows sediment expert to examine spatial distributions of seafloor sediment types and discriminate among them. This method is expected to reduce expensive bottom-sampling programs. The research examined multibeam data collected from Indonesia Exploration 2010 Project. This project employed a Kongsberg EM302 multibeam system to collect seafloor topography and backscatter data at Sangihe Talaud Sea, North Sulawesi. The average depth of the area study is approximately $2400 \mathrm{~m}$. The research applied the Angular Response Curve (ARC) method to analyze the echo strength of the backscatter as a function of the grazing angle. The range of backscatter intensity in this area is from $-9 \mathrm{~dB}$ to $67 \mathrm{~dB}$. Based on the backscatter data, there are five types of sediment in this area: clay, mud, gravel, sand, and boulder.
\end{abstract}

\section{Introduction}

The multibeam echo-sounder (MBES) systems use an acoustics signal to reveal unprecedented detail of the bed morphology and bed form migration, whilst the backscatter signal from the bed can also be utilized to provide information on the bed roughness [3]. MBES systems also provide acoustic returns from within the water column that can image within the flow, and this ability has recently been applied for both object detection and visualization [4]. The acoustic wave emitted by a MBES reflects from obstacles of various natures in the water column and at the boundary interfaces of the medium. The returning energy from the seafloor, called backscatter, is related to the physical nature of the sea bottom as well as to some characteristics of the transmission and reflection (e.g., the angle of incidence and the pulse-length) of the incident signal [2].

The backscatter intensity of the acoustic signal is reflected by the seafloor follows the angular response function which shows the relationship between the value of the backscatter intensity and the angular response. This relationship can be used to determine the seafloor sediment type on the seafloor and to identify the type and distributions of the

\footnotetext{
"Corresponding author: guruh@geodesy.its.ac.id
} 
morphological segregation of the seabed sediments [1]. The backscatter imagery provides a representation of the seafloor which is a mixture of both bathymetric and sedimentological signatures. The acoustic response of seabed varies as the sediment type, roughness, grain-size, compaction, and slope change. In addition, returned backscatter energy depends not only on the seafloor physical properties but also on the sonar configuration, water column propagation, and measurement geometry.

The geometric and radiometric corrections are necessary to get backscatter data which represent an inherent property of seabed that reflects its physical properties. In this case, to a first order, the geometric and radiometric corrections have been applied by the manufacturer [8]. A number of different approaches to characterization via backscatter have been developed with the primary aim of acoustic segmentation; that is, mapping discrete geographical areas of the seafloor with the same acoustic signature. These techniques have also been utilized to extract different properties from the backscatter data $[5]$.

The research focused on backscatter data analysis to identify sediment distribution in Sangihe Talaud water, North Sulawesi. The research analyzed a relationship between the backscatter intensity value and the angular response. The backscatter mosaic results generated from the acoustic signal processing are inversely proportional to the given spatial resolution. When an angular curve produces a high value, the resulting spatial resolution will be low [3]. The research examined multibeam data which is collected from Indonesia Exploration 2010 Project. This project utilized a Kongsberg EM302 multibeam system to acquire seafloor topography and backscatter data.

\section{Data and Research Area}

The research used multibeam data from the Leg 2 of the Expedition Indonesia Exploration 2010 Project. This project used an EM302 Kongsberg system which is attached at vessel survey RV Okeanos Explorer. This $30 \mathrm{kHz}$ multibeam system is designed to perform seabed mapping with high resolution and accuracy to a maximum depth of more than $7000 \mathrm{~m}$. The system has up to 432 soundings per swath with pointing angles automatically adjusted according to achievable coverage or operator defined limits. The multibeam system equipped with dual swath (two swaths per ping) system. The transmit fan is duplicated and transmitted with a small difference in along-track tilt. The applied tilt takes into account depth, coverage and vessel speed to give a constant sounding separation along-track. In dual swath mode, 2 swaths are generated per ping cycle, with up to 864 soundings. The beam spacing is equidistant or equiangular.

EM302 uses both CW and FM pulse forms. FM sweep with pulse compression on reception is used to increase the maximum useful swath width. The FM pulses will also increase the resolution compared to $\mathrm{CW}$ pulses of the same length. The transmit fan is split in several individual sectors with independent active steering. This allows stabilization which compensates for the vessel movements: yaw, pitch and roll. Each transmit sector has individual beam focusing. The EM 302 transducers are modular linear arrays in a Mills cross configuration with separate units for transmit and receive [10].

The EM302 was utilized to collect the data from June 23rd to June 25th, 2010. A sea level observation was also conducted to correct the depth measurement from multibeam. This observation is located at Port Bitung station and started from June to July, 2010. A Sound Velocity Profiler measurement was also conducted on vehicle during MBES acquisition. The research area is located in west side of Sangihe Island, North Sulawesi Province. The area is bound with geographical coordinates $2^{\circ} 01^{\prime} \mathrm{LU}-6^{\circ} 24^{\prime} \mathrm{LU}$ and $124^{\circ}$ $45^{\prime} \mathrm{BT}-128^{\circ} \mathrm{BT}$. The average depth of the area study area is approximately $2400 \mathrm{~m}$. Fig. 1 
shows the location of the research area. The research utilized Swathed, a MBES processing software developed by Hughes Clarke from UNH.

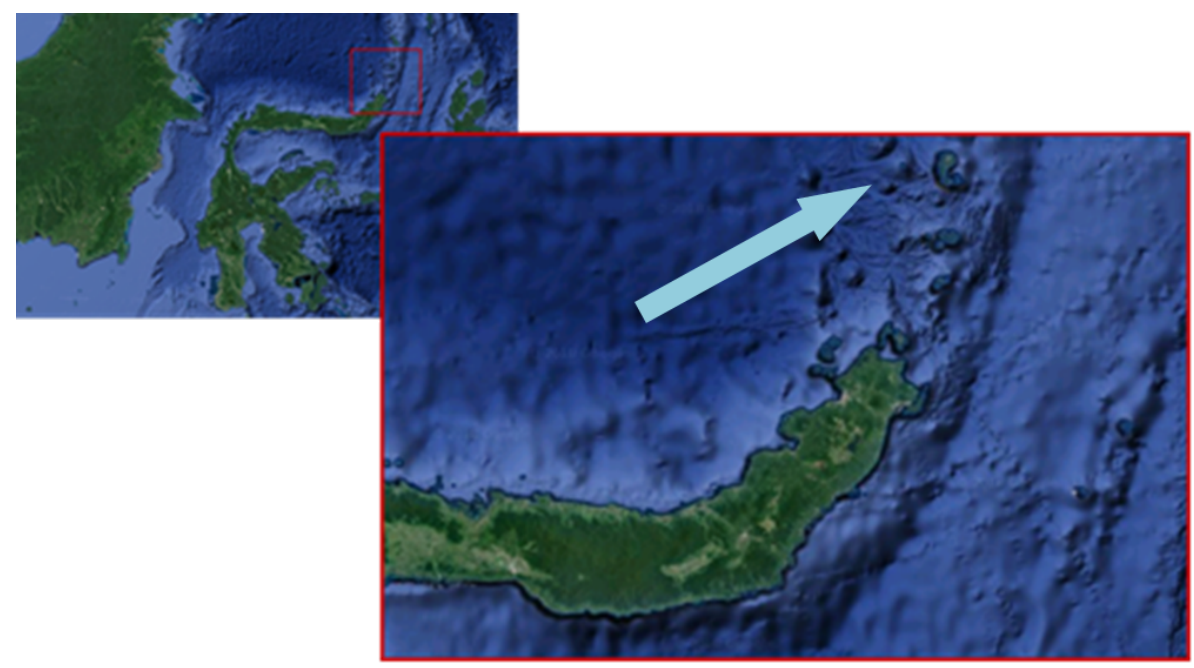

Fig. 1. Map of the research area. Blue arrow shows the location of study site in Sangihe Talaud Sea, North Sulawesi.

\section{Methodology}

Bathymetric data collected using the Kongsberg SIS software is fully corrected for ship's motion, navigation and sound velocity [9]. Application of corrected tides and bathymetric data cleaning are processed using the Swathed and tide reference data provided by BIG (Indonesia Geospatial Information Bureau). Next, is creating a gridded bathymetry surface using processed data. In this research, backscatter data were processed using the Swathed as well. The backscatter data is imported directly from the datagrams. The data used in this research are from line 15 to line 31. Data acquisition was performed two days from 23-24 June 2010 by R/V Okeanos Explorer. Raw data is then processed through unravel process and convert to Ocean Mapping Group format: *.merged is the format for bathymetry data and *.ss is for backscatter data.

Tidal correction is required to achieve the depth even though it is not essential as the area is classified as deep water. The tidal data during the acquisition of the MBES data is adjusted to *.bin format to be corrected with the *.merged file. The MBES data cleaning process is performed on the Swathed profile tab with the median filter which can eliminate spikes with a significant different depth value from the median depth value. After the data free from spikes, a Digital Terrain Model (DTM) was created using parameters as follow: $5 \mathrm{~m}$ per pixel, beam width $1.0^{\circ}$, vertical exaggeration 1.0. The DTM file is in $\mathrm{r} 4$ format then is exported to ESRI format with R4toESRI command to be processed further. The DTM created from this data can be seen in Fig 2.

In order to achieve scattering values, the backscatter is corrected to remove nadir stripping, eliminating beam pattern variation, and georefencing. The next step is creating a backscatter mosaic with mos 2 command. The mos file is then exported to ESRI format with the r4toESRI command. The backscatter mosaic file is processed with ArcMap to classify the sediment type of the backscatter value obtained from the pixel value (DN = Digital Number) in the mosaic which is then converted to 24-bit decibels (dB). The decibel 
and transmit angle values of MBES (grazing angle) are then made graphs to obtain the backscatter strength and the sediment type relationships.

The following are the corrections steps foresaid to achieve a corrected backscatter image: [a] correction of transmission losses associated with absorption and oblique range, [b] application of calibration gains, and [c] correction for the instantaneous ensonified area. The output of this reduction process is considered as the best estimate of the absolute backscatter angular response for the survey area.

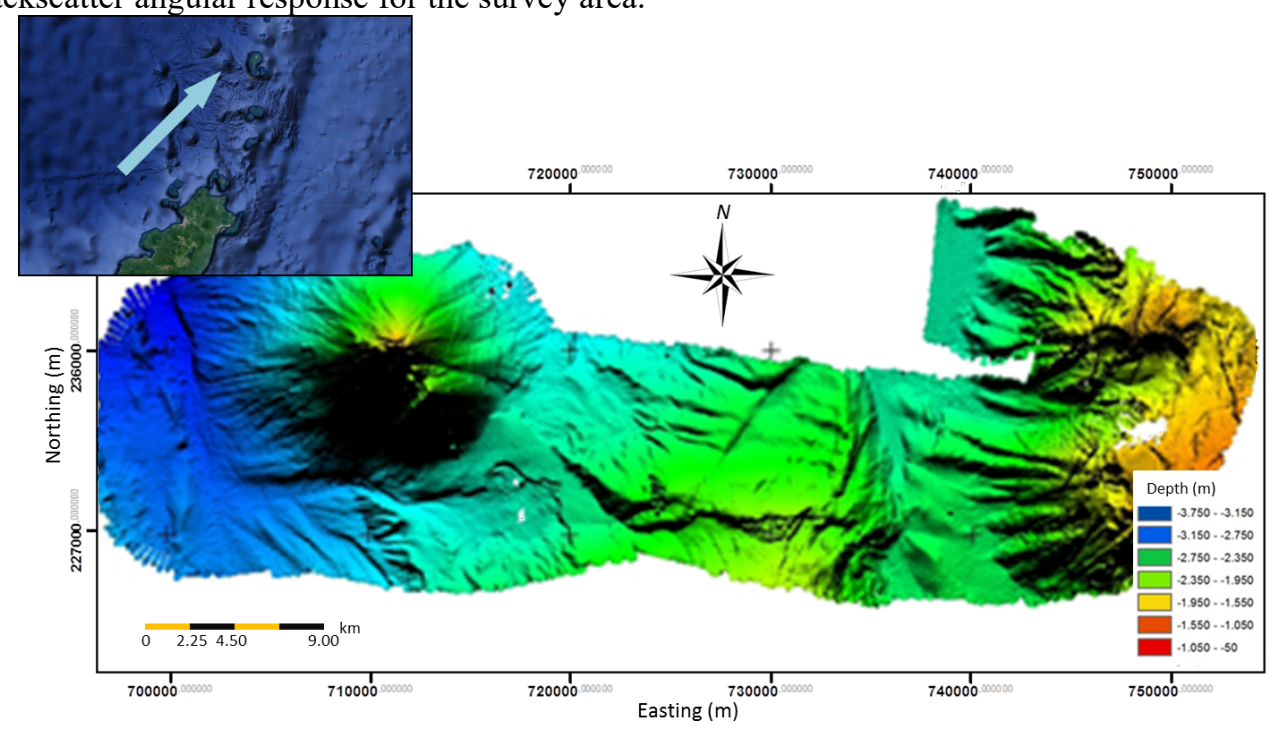

Fig. 2. The Digital Terrain Model (DTM) of the research area created from MBES data. The location of the DTM is pointed by blue arrow.

\section{Results and Analysis}

\subsection{Bathymetry and tide}

Horizontal positioning method used in the research is a differential positioning using a C-NAV DGPS system. This system can provide a $2.0 \mathrm{~m}$ accuracy. Most of datasets used in this research were collected by Kongsberg EM302 multibeam system. In the processing of MBES raw data, cleaning data used to eliminate the noise and spike. This can be from several factors such as under water biota activity, water bubbles, and reflective objects the MBES acoustic signal before the signal arrives at the bottom of the waters.

In order to get the depth, the MBES data then corrected with the tides data. The tide used in the research is observed tide from Bitung Station, North Sulawesi. The duration for the tide observation is 1 month during the time of MBES data acquisition (June $24^{\text {th }}-$ July $\left.24^{\text {th }}, 2010\right)$. The tide observation can be seen in Fig. 3. 


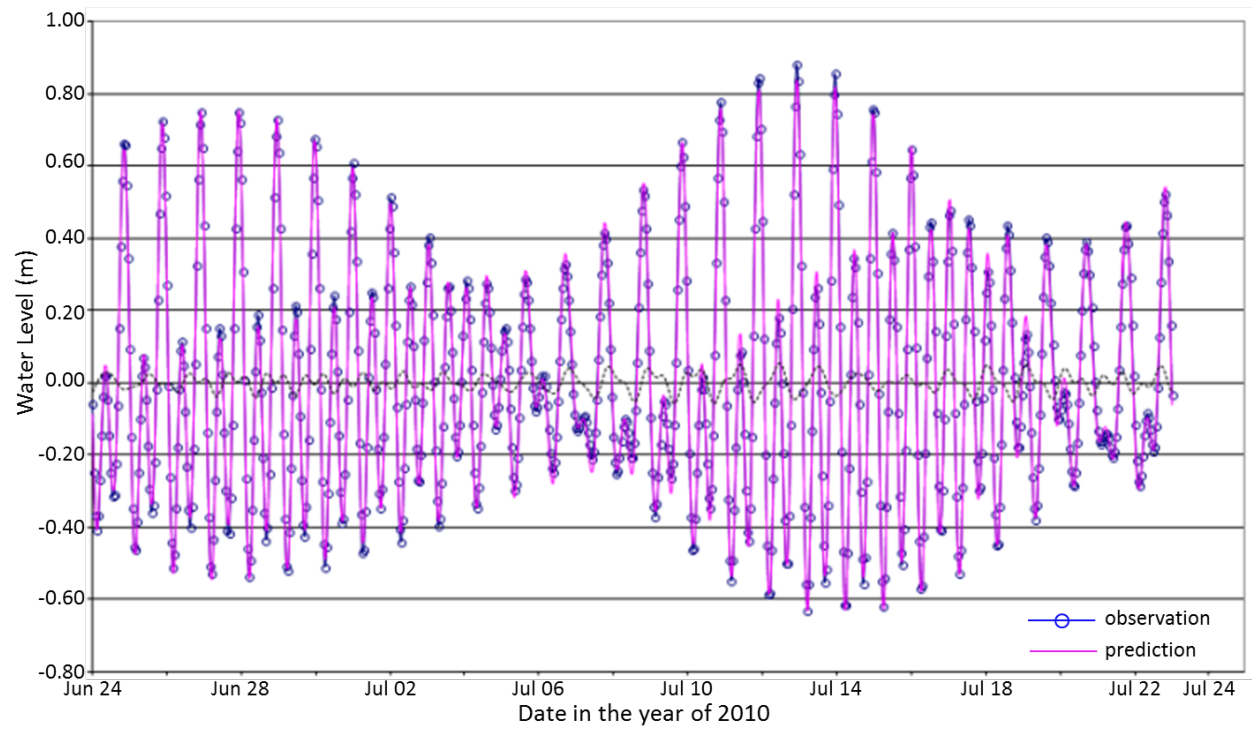

Fig. 3. Tide observation in the research area. The observed tide is represented by blue line, and the magenta line represents the tide prediction. The black line is the difference between the tide observation and prediction.

\subsection{Analysis of backscatter strength}

After the correction step for each raw data line, then each line is combined to develop a backscatter mosaic. The classification of the sediment types was conducted by looking at the backscatter strength of the echo return in the mosaic. The strong scatter is represented by black color and it shows hard sediments. Vice versa, the weak scatter is represented by white color and it shows soft sediments. Based on the backscatter mosaic, the range of backscatter strength is from $-10 \mathrm{~dB}$ to $-67 \mathrm{~dB}$. Furthermore, this mosaic is processed using Arc map to classify the sediment on the seafloor. The backscatter strength mosaic can be seen in Fig. 4.

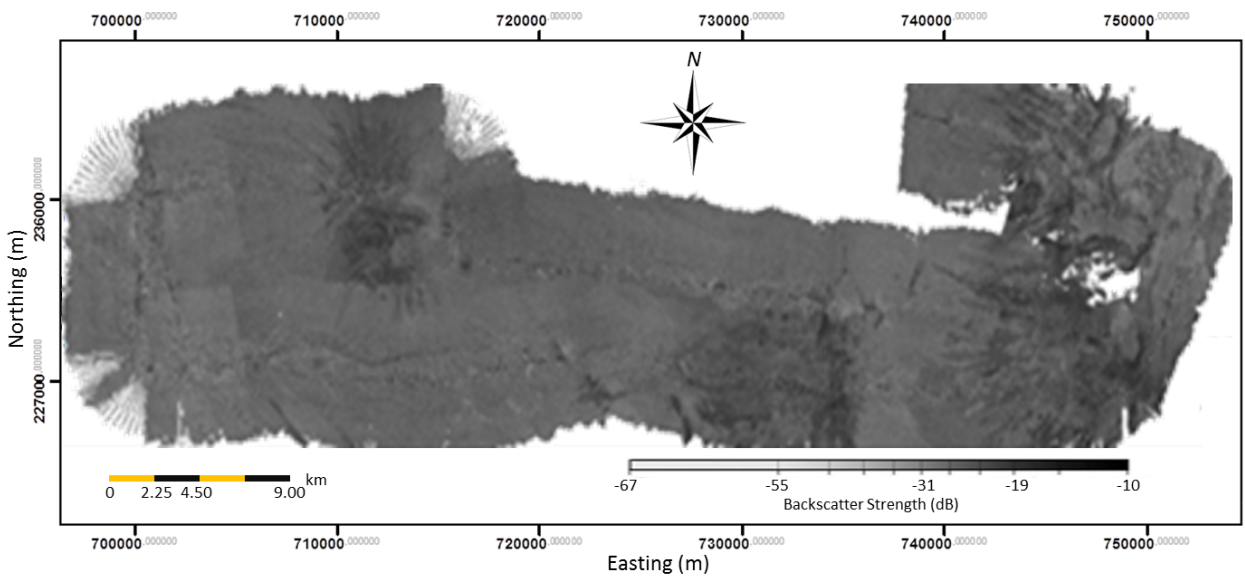

Fig. 4. The backscatter image of the research area. The backscatter strength is represented by grey scale color. White color represents a weak intensity and black color represents a strong intensity. 


\section{Discussions}

\subsection{Sediment distribution based on backscatter value}

The backscatter strength is in a Digital Number. The magnitude of the backscatter strength is derived from three beam sweeping zone of the MBES which are the nadir zone, the oblique corner zone, and the angular critical zone. In the area which is composed by rock outcrop has a very strong scattering value (high intensity). This intensity ranges from $237 \mathrm{DN}$ to $211 \mathrm{DN}$ or from $-9 \mathrm{~dB}$ to $-67 \mathrm{~dB}$ in decibel unit. The area composed by boulder has a backscatter value from $237 \mathrm{DN}$ to $217 \mathrm{DN}$ or from $-9 \mathrm{~dB}$ to $-18 \mathrm{~dB}$. The areas composed by gravel have a backscatter value from $209 \mathrm{DN}$ to $187 \mathrm{DN}$ or $-23 \mathrm{~dB}$ to $-34 \mathrm{~dB}$. The area which is dominated by sand has a backscatter value from $185 \mathrm{DN}$ to $159 \mathrm{DN}$ or $-35 \mathrm{~dB}$ to $48 \mathrm{~dB}$ in decibel unit. The area contains mud has backscatter value ranges from $157 \mathrm{DN}$ to $137 \mathrm{DN}$ or from $-49 \mathrm{~dB}$ to $-59 \mathrm{~dB}$. Area composed by clay has very low backscatter strength (low intensity) from $135 \mathrm{DN}$ to $127 \mathrm{DN}$ or $-60 \mathrm{~dB}$ to $-67 \mathrm{~dB}$.

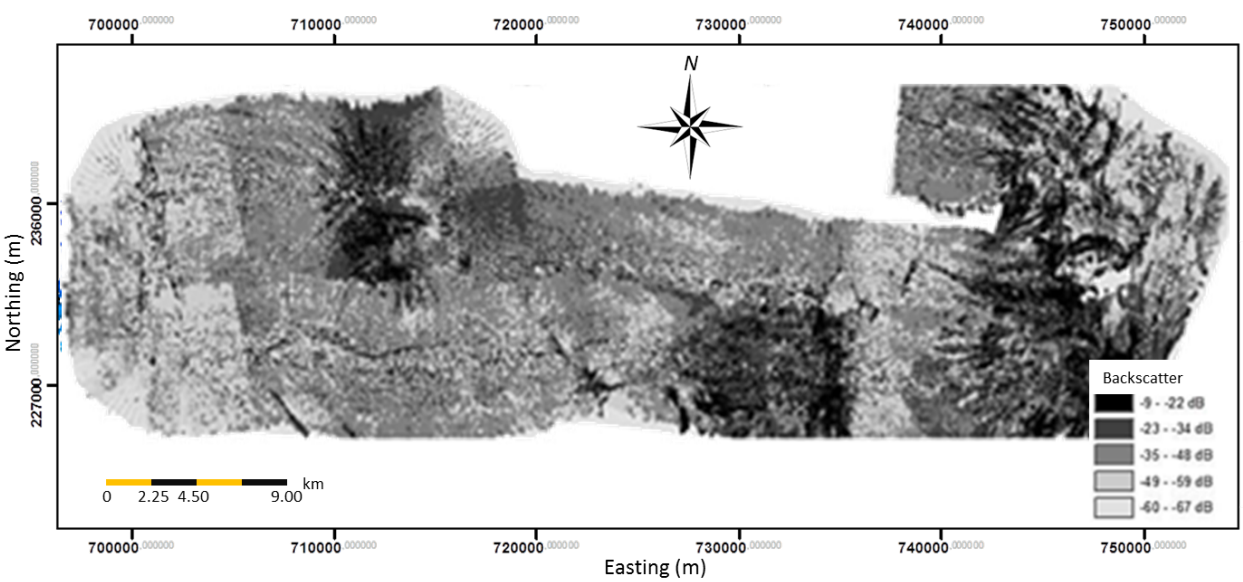

Fig. 5. Distribution of backscatter value. The backscatter values is classified into 5 types.

Fig. 5 shows the classification of the backscatter values. The values range from $-9 \mathrm{~dB}$ to $-67 \mathrm{~dB}$, these values have been converted from DN value. The range for the backscatter value is classified into 5 classes according to the type of sediment composed the seafloor. The black color in the mosaic shows the value a strong backscatter which indicates a hard sediment type. While the bright color in the mosaic indicates the backscatter value is a soft sediment type.

Fig. 6 shows the backscatter strength with a range of values $-9 \mathrm{~dB}$ to $-67 \mathrm{~dB}$. There are 5 types of sediment which covers the seafloor. Based on the sediment classification, the research area is dominated by mud with backscatter values ranges from $-49 \mathrm{~dB}$ to $-59 \mathrm{~dB}$. 


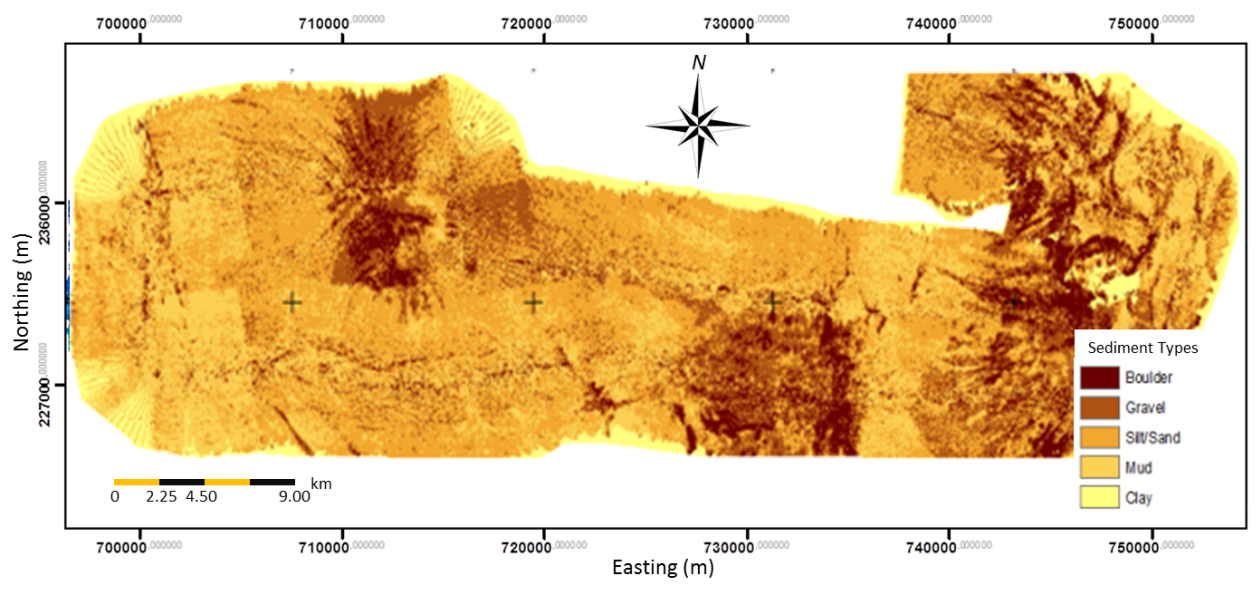

Fig. 6. Sediment classification based on backscatter strength. There are five types of sediment cover the seafloor.

\subsection{Angular Response Curve}

The corrected correlation obtained from the extraction of backscatter values of each sampling line samples are then plotted in the reflection angle / grazing angle curve in order to determine the relationship of the sediment type based on the MBES reflection angle to the bottom surface of the waters.

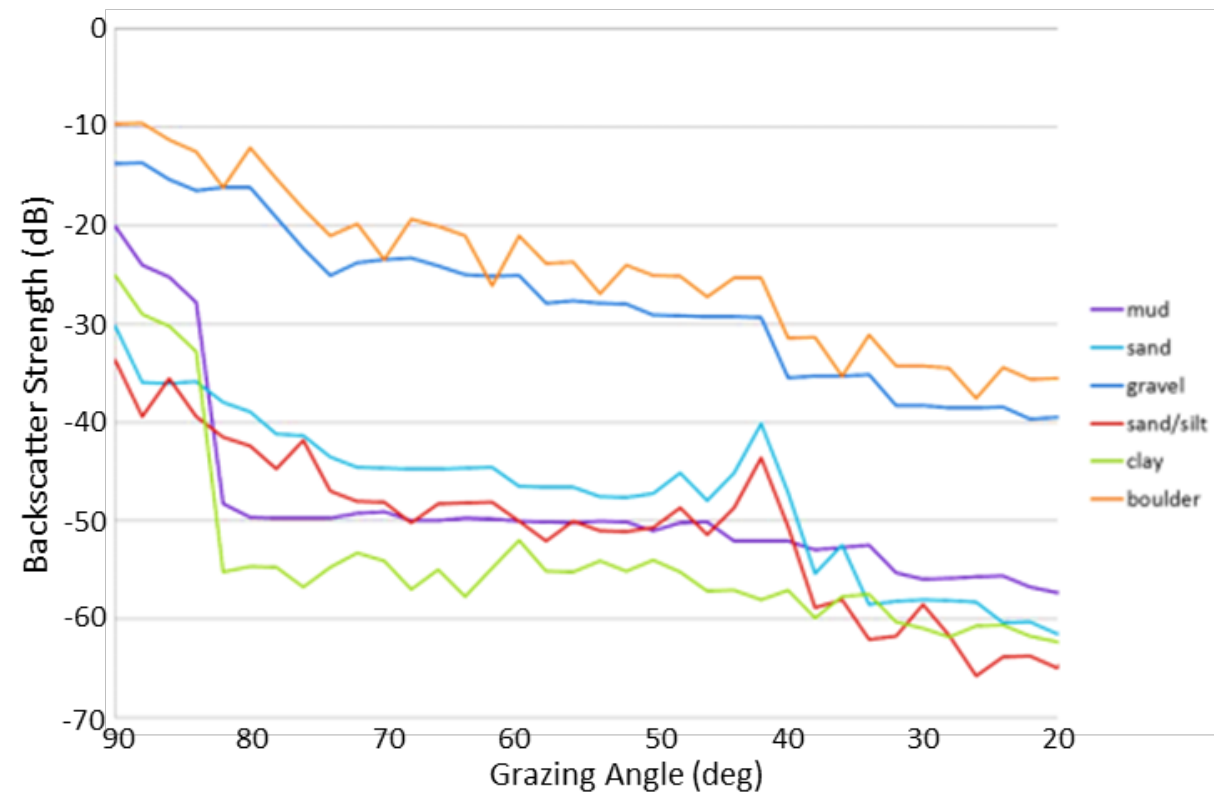

Fig. 7. The relation between the grazing angle and the backscatter strength. Generally, as the grazing angle decreases, the backscatter intensity will also decrease. The maximum backscatter strength is in nadir.

Fig. 7 shows the relationship between the backscatter strength and the grazing angle. The different color on the curve represents the backscatter strength of each sediment types. 
The response of the backscatter strength to the grazing angle on the nadir is very strong due to the surface flattening of the gravel sediments which allows reflecting the acoustic signal by scattering the acoustic signal. However, when grazing angle is $70^{\circ}-60^{\circ}$ there is a significant decrease in backscatter value. This occurs due to the oblique angle of the acoustic signals received by the transducer. At the critical angle is from $30^{\circ}$ to $10^{\circ}$, the acoustic signal is reflected in a small angle so that the backsliding value is weakened or even lost.

Similar to the angular response curve of the gravel sediment type, the angular response curve of the sand sediment type has a very strong backscatter value at nadir, and decreases in the slope angle area or $70^{\circ}-40^{\circ}$ grazing angle. However, at the critical angle, the backscatter value increases and forms a peak curve at about $30^{\circ}$ of grazing angle. For the mud sediment type, at the nadir angle, the backscatter value still has a strong intensity dominated by scattering volume, but when the grazing angle is $80^{\circ}$ and declining, the mudbacks backscatter value weakens with a smoothly decreasing curve at $40^{\circ}$ grazing angle.

\section{Conclusions}

The analysis of the relationship between backscatter strength and grazing angle is confirmed as a promising technique for a quantitative automated processing of large datasets of seafloor backscatter. This research successfully applied this technique. The availability of absolute calibrated process with appropriate data reduction was the key to the success of this approach. The result from the research shows a good clustering of different sediment types. This could be a relevant basis for a reflectivity angular response types to classify the sediment distribution. Distribution of corrected scattering value in the research area has a maximum repository value of $-10 \mathrm{~dB}$ and a minimum of $-67 \mathrm{~dB}$ and it has a DN range from 237DN to $121 \mathrm{DN}$. The results of the distribution of sediment types based on the analysis of backscatter value using an Angular Response Curve method is as the following: [a] $-9 \mathrm{~dB}$ to $-22 \mathrm{~dB}$ is boulder, [b] $-23 \mathrm{~dB}$ to $-34 \mathrm{~dB}$ is gravel, [c] $-35 \mathrm{~dB}$ to $48 \mathrm{~dB}$ is sand, [d] $-49 \mathrm{~dB}$ to $-59 \mathrm{~dB}$ is mud, and [e] $-60 \mathrm{~dB}$ to $-67 \mathrm{~dB}$ is clay.

The authors would like to thank BPPT and NOAA as the data provider and Dr. Hughes Clarke for the Swathed, a multibeam processing software.

\section{References}

1. R. Che Hasan, D. Ierodiaconou , L. Laurenson, A. Schimel. Integrating multibeam backscatter angular response, mosaic and bathymetry data for benthic habitat mapping. PLoS One. 9(5): e97339. 10.1371/journal.pone.0097339 (2014)

2. C. De Moustier. Angular dependence of $12 \mathrm{kHz}$ sea-floor acoustic backscatter. Journal of Acoustical Society of America, pp. 522-531 (1991)

3. L. Fonseca, L. Mayer. Remote estimation of surficial seafloor properties through the application angular range analysis to multibeam sonar data. Marine Geophysical Researches. 28(2): 119-126. 10.1007/s11001-007-90194(2007)

4. M. Giuseppe, B. Calder B. Remote identification of a shipwreck site from MBES backscatter. Journal of Environmental Management Volume 111, 30 November 2012, Pages 44-52 (2012) 
5. E. Hammerstad. Backscattering and seabed image reflectivity, EM Technical Note (2000)

6. J. E. Hughes Clarke. Towards remote seafloor classification using the angular response of acoustic backscatter: a case study from multiple overlapping GLORIA data. IEEE Journal of Oceanic Engineering, Volume 19, pp. 112-127 (1994)

7. H. Manik, D. Yulius. Development and application of MB system software for bathymetry and seabed computation. International Journal of Software Engineering and Its Applications (2015)

8. D. G. Pratomo. Coupling of repetitive multibeam surveys and hydrodynamics modelling to understand bedform migration and delta evolution. The University of New Brunswick: Canada (2016)

9. SIS. Seafloor Information System, Kongsberg ME70 Operator Manual. Kongsberg Maritime (2010)

10. X. Lurton. An Introduction to Underwater Acoustics: Principles and Applications (second ed.), Springer, published in association with Praxis Publishing, Chichester, UK, Heidelberg; New York (2010) 